\title{
Recruitment and subsequent proliferation of bone marrow-derived cells in the postischemic kidney are important to the progression of fibrosis
}

\author{
Hee-Seong Jang, ${ }^{1,2}$ Jee In Kim, ${ }^{3}$ Sang Jun Han, ${ }^{1}$ and Kwon Moo Park ${ }^{1,2}$ \\ ${ }^{1}$ Department of Anatomy and BK21 Plus Biomedical Convergence Program, Kyungpook National University School of \\ Medicine, Daegu, Republic of Korea; ${ }^{2}$ Cardiovascular Research Institute, Kyungpook National University School of Medicine, \\ Daegu, Republic of Korea; and ${ }^{3}$ Department of Molecular Medicine, Keimyung University School of Medicine, Daegu, \\ Republic of Korea
}

Submitted 8 January 2014; accepted in final form 10 April 2014

\begin{abstract}
Jang HS, Kim JI, Han SJ, Park KM. Recruitment and subsequent proliferation of bone marrow-derived cells in the postischemic kidney are important to the progression of fibrosis. Am J Physiol Renal Physiol 306: F1451-F1461, 2014. First published April 16, 2014; doi:10.1152/ajprenal.00017.2014.—Acute kidney injury (AKI) is an independent risk factor of the development of chronic kidney disease. Kidney fibrosis is a typical feature of chronic kidney disease and is characterized as an expansion of the interstitium due to increases in extracellular matrix molecules and interstitial cells caused by accumulations of extrarenal cells and by the proliferation or differentiation of intrarenal cells. However, the role of bone marrowderived cells (BMDCs) in AKI-induced kidney fibrosis remains to be defined. Here, we investigated the role of BMDCs in kidney fibrosis after ischemia-reperfusion injury (IRI)-induced AKI in green fluorescent protein (GFP)-expressing bone marrow chimeric mice. IRI resulted in severe fibrotic changes in kidney tissues and dramatically increased interstitial cell numbers. Furthermore, GFP-expressing BMDCs accounted for $>80 \%$ of interstitial cells in fibrotic kidneys. Interstitial GFP-expressing cells expressed $\alpha$-smooth muscle actin (a myofibroblast marker), fibroblast-specific protein-1 (a fibroblast marker), collagen type III, and F4/80 (a macrophage marker). Over $20 \%$ of interstitial cells were bromodeoxyuridine-incorporating (proliferating) cells, and of these, $80 \%$ cells were GFP-expressing BMDCs. Daily treatment of IRI mice with apocynin (a NADPH oxidase inhibitor that functions as an antioxidant) from the day after surgery until euthanization slightly inhibited these changes with a small reduction of fibrosis. Taken together, our findings show that BMDCs make a major contribution to IRI-induced fibrosis due to their infiltration, subsequent differentiation, and proliferation in injured kidneys, suggesting that BMDCs be considered an important target for the treatment of kidney fibrosis.
\end{abstract}

ischemia; fibrosis; bone marrow-derived cell; fibroblast; macrophage

FIBROSIS IS A COMMON CHARACTERISTIC of the tissue repair process, but excessive fibrosis results in the loss or malfunction of organs. Fibrosis is a typical feature of chronic kidney disease and presents as an expansion of the interstitial area. This expansion is mainly caused by the excessive production of extracellular matrix (ECM) molecules by activated interstitial fibrogenic cells and by increases in the interstitial cell population by myofibroblasts, fibroblasts, and macrophages $(7,42)$. Although it has been commonly believed that increases in interstitial cell in fibrotic kidneys are associated with resident kidney fibroblasts, recent evidence suggests that these increases are caused by cells from various sources, such as the

Address for reprint requests and other correspondence: K. M. Park, Dept. of Anatomy, Cardiovascular Research Institute and BK21 Plus, Kyungpook National Univ. School of Medicine, 101 Dongindong, Junggu, Daegu 700-422, Korea (e-mail: kmpark@knu.ac.kr). differentiation of pericyte/perivascular fibroblasts, bone marrow (BM)-derived cells (BMDCs), or epithelial cell/endothelial cell transitions to mesenchymal cells $(17,22,28)$. Furthermore, it has recently been demonstrated that increases in interstitial cell are caused by intrarenal and extrarenal cells (28, 44). We (22) have recently reported that BMDCs are a main contributor to increases in the interstitial cell population in kidneys during unilateral ureteral obstruction (UUO) and suggested that the regulation of this process offers a means of developing strategies and therapeutics to prevent or treat fibrotic kidney disease. However, the cellular origins of the interstitial cells observed in acute kidney injury (AKI)-induced kidney fibrosis have not been determined.

The progression of fibrosis is associated with the production of reactive oxygen species (ROS) and the subsequent oxidative stress and inflammatory response in various organs, including the kidneys $(11,37,42)$. Furthermore, the inflammatory response is associated with the generation of ROS/oxidative stress, and, similarly, ROS/oxidative stress are associated with inflammation $(6,36)$. For example, we found that inhibition of ROS/oxidative stress attenuated fibrotic changes in injured kidney by inhibiting leukocyte infiltration $(22,24)$. In addition, we found that the responses to ROS scavenging are dependent on the kidney cell type and on the timing and duration of treatment in an ischemia-reperfusion injury (IRI) model of kidney regeneration and fibrosis (24). It has also been suggested that ROS are important fibrogenic factors in chronic allograft nephropathy after transplantation (14). The previous findings suggest that ROS/oxidative stress are critical determiners of consequences such as fibrosis.

Accordingly, the present study was undertaken to define the role of BMDCs during fibrotic progression, and the molecular mechanisms responsible, after kidney IRI in mice.

\section{MATERIALS AND METHODS}

Animal preparation. Eight-week-old male mice weighing 20-25 g were used throughout the study. C57BL/6 and enhanced green fluorescent protein (eGFP)-expressing mice [C57BL/6-TgN(ACTbEGFP)10sb] were purchased from Koatech (Gyeounggido, Korea) and the Jackson Laboratory, respectively. All animal experiments were approved by the Institutional Animal Care and Use Committee of Kyungpook National University. Animals were anesthetized with pentobarbital sodium (60 mg/kg body wt, Sigma; St. Louis, MO) before surgery. Kidney ischemia was induced as previously described (25). In brief, kidneys were exposed via flank incisions. Mice were subjected to 30 min of unilateral renal ischemia using nontraumatic microaneurysm clamps (Roboz Surgical Instruments, Washington, DC). The incisions were closed temporarily during ischemia. Reperfusions were visually confirmed after clamp removal. Body temperatures were maintained 
at $36.5-37.5^{\circ} \mathrm{C}$ during surgery. Mouse kidneys were harvested at 9 and 21 days after surgery. To detect proliferating cells, mice were treated with 5-bromo-2'-deoxyuridine (BrdU; $50 \mathrm{mg} / \mathrm{kg}$ body wt daily, Sigma) beginning at 2 days before surgery until the day of death. Some mice were treated with apocynin $(10 \mathrm{mg} / \mathrm{kg}$ body wt daily, Calbiochem), a putative NADPH oxidase inhibitor that acts as an antioxidant $(3,5)$, beginning at 1 day after surgery until the day of death (22). Sham surgery was performed in an identical manner but without clamping of the renal pedicle. For biochemical and histological experiments, kidneys were snap frozen in liquid nitrogen and perfusion fixed in $30 \mathrm{ml}$ PBS for 2 min and then in 4\% paraformaldehyde, $75 \mathrm{mM}$ L-lysine, and $10 \mathrm{mM}$ sodium periodate (PLP solution; Sigma) overnight. Tissues were stored in a deep freezer $\left(-80^{\circ} \mathrm{C}\right)$ until required.

BM transplantation. BM chimeric mice with BM expressing eGFP were generated as previously described (16). Briefly, eGFP mice (8-10 wk old) were euthanatized with an overdose of pentobarbital sodium, and the BM was harvested from femurs and tibias. Recipient
C57BL/6 mice ( 8 wk old, male) were irradiated with 8 Gy using a cesium-137 source irradiator, and 10 million eGFP-expressing BM cells were then injected into each irradiated recipient via a tail vein. BM-transplanted mice were left to reconstitute BM for $8 \mathrm{wk}$. When BM transplantation failed, irradiated mice started to die at about 6 days after irradiation treatment.

Histology. Perfusion-fixed kidneys were excised and placed in PLP solution overnight at $4{ }^{\circ} \mathrm{C}$, and $4-\mu \mathrm{m}$ paraffin-embedded kidney sections were obtained using a microtome (Leica, Bensheim, Germany). Sections were stained with periodic acid-Schiff (PAS) or Masson's trichrome staining as previously described (19). PAS-stained kidney sections were visualized under a stereomicroscope (Leica, Wetzlar, Germany) and a Nikon Fx35. Collagen deposition was quantified using the i-solution DT image acquisition and analysis program (iMT i-solution, Vancouver, BC, Canada) using the Nikon Fx35 in 10 fields in the outer medulla of each kidney. Morphological damage levels in PAS-stained kidney sections were scored as previously described (20). Briefly, 50 tubules in the outer medullar region were scored from
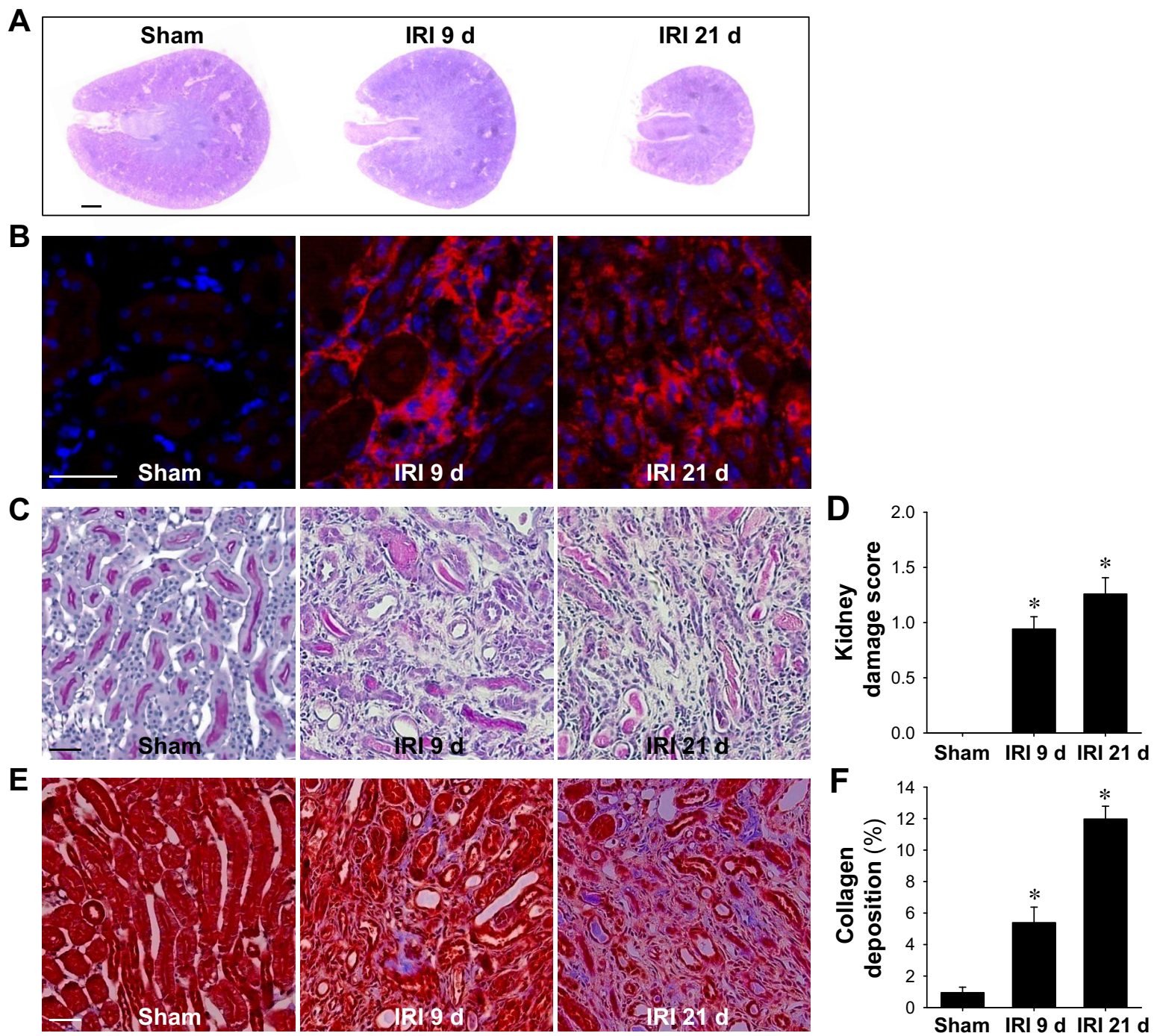

Fig. 1. Atrophy and tubulointerstitial fibrosis in kidneys after ischemia-reperfusion injury (IRI). Mice were subjected to either unilateral IRI or sham operation (sham). Kidneys were harvested at 9 or 21 days (d) after surgery. Periodic acid-Schiff (PAS; $A$ and $C$ ), immunofluorescent $(B)$, and Masson's trichrome $(E)$ staining were performed as described in MATERIALS AND METHODS. A: photomicrograph of a PAS-stained cross-section of the kidney taken with a stereomicroscope. B: OCT-embedded kidney sections were immunostained with anti-F4/80 (red) antibody. 4',6-Diamidino-2-phenylindole (DAPI) was used to detect nuclei (blue). Pictures were taken of the outer medulla. $D$ and $F$ : ten fields of the outer medulla per kidney $(n=4-5$ per group) were randomly selected to evaluate kidney damage and collagen deposition. Scale bar in the stereoscopic microscopic image $=1 \mathrm{~mm}$; scale bars in the optical and fluorescence microscopic images $=50 \mu \mathrm{m}$. Results are presented as means \pm SE. $* P<0.05$ vs. sham. 
0 to 3 as follows: $0=$ no damage; $1=$ mild damage with rounding of epithelial cells and dilated tubular lumen; $2=$ severe damage with flattened epithelial cells, loss of nuclear staining, dilated lumen, and congestion of lumen; and $3=$ destroyed tubules with flat epithelial cells lacking nuclear staining and congestion of lumen. At least four kidneys per experimental condition were used. Ten fields per kidney were scored.

Immunofluorescence staining. Immunofluorescence staining was performed using OCT- or paraffin-embedded kidney sections, as previously described $(21,26)$. The antibodies used were as follows: GFP (Santa Cruz Biotechnology, Santa Cruz, CA), fibroblast-specific protein (FSP)-1 (Novus, Littleton, CO), collagen type III (Abcam, Cambridge, MA), $\alpha$-smooth muscle actin ( $\alpha$-SMA; Sigma), Nox2 (Novus, Littleton, CO), and BrdU (Serotec, Oxford, UK). Sections were observed under a Nikon Fx35. To identify interstitial cells, kidney sections were visualized under a V-2A fluorescence filter, which allowed kidney morphologies and 4',6-diamidino-2-phenylindole (DAPI)-stained nuclei to be observed (22). Numbers of interstitial cells were determined by counting DAPI-positive cells in interstitium. Numbers of cells were determined in 10 fields/kidney. In a previous study (22), we confirmed that the GFP signals observed by immunofluorescence staining with GFP antibody are no different from original GFP signals. Collagen type III areas were determined using i-solution software (iMTechnology) and averaged in 10 fields/kidney, as previously described (22).

Western blot analysis. Western blot analyses were performed as previously described (34). The antibodies used were as follows: GFP (Santa Cruz Biotechnology), $\alpha$-SMA (Sigma), collagen type III (Abcam), Nox2 (Novus), and GAPDH (Santa Cruz Biotechnology). ImageJ software (National Institutes of Health, Bethesda, MD) was used to quantify band densities.

Statistics. Results are expressed as means \pm SE. Statistical differences between groups were determined using Student's $t$-test. Each experimental group consisted of at least four mice. Differences between groups were considered statistically significant when $P$ values were $<0.05$.

\section{RESULTS}

IRI recruited BMDCs into kidneys. First, we confirmed that IRI led to the development of fibrosis by PAS and Masson's trichrome staining in the kidney. As shown in Fig. 1, IRI kidneys gradually shrank with time (Fig. 1A) and presented tubular atrophy, expansion of interstitial spaces, and increases in the interstitial cell population, including macrophages (Fig. $1, B-D)$. Collagen deposition also gradually increased in IRI kidneys with time (Fig. $1, E$ and $F$ ). These results indicate that IRI resulted in fibrosis. Next, to evaluate the involvement of BMDCs in the progression of fibrosis, we determined the numbers of GFP-positive cells and GFP expression levels in IRI kidneys using eGFP-expressing BM chimeric mice. Initially, we confirmed the reconstitution of $\sim 95 \%$ eGFP-BM in eGFP-BM chimeric mice (22). IRI greatly increased interstitial cell population, as determined by DAPI staining (Fig. 2A). GFP-positive cell numbers also greatly increased in the interstitium of IRI kidneys and accounted for $>80 \%$ of interstitial cells at 9 and 21 days after IRI (Fig. 2A). The level of GFP protein also increased $\sim 10$-fold after IRI (Fig. $2 B$ ). These findings indicate that BMDCs play a major role in the establishment of an elevated interstitial cell population after IRI.

Since interstitial area expansion in fibrotic kidneys is associated with increased deposition of ECM proteins, including collagens (19), we investigated whether infiltrating GFP-positive cells had the features of myofibroblasts (major producers

A
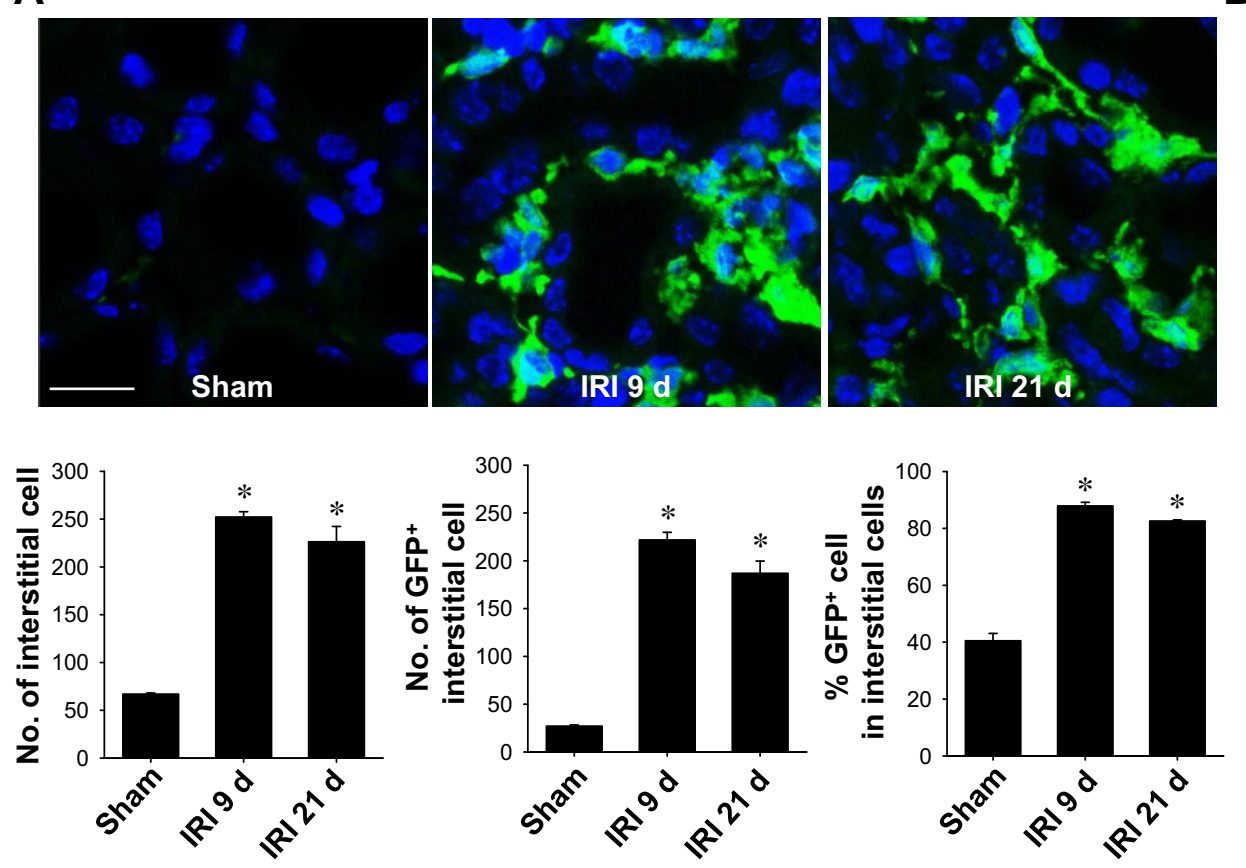

B
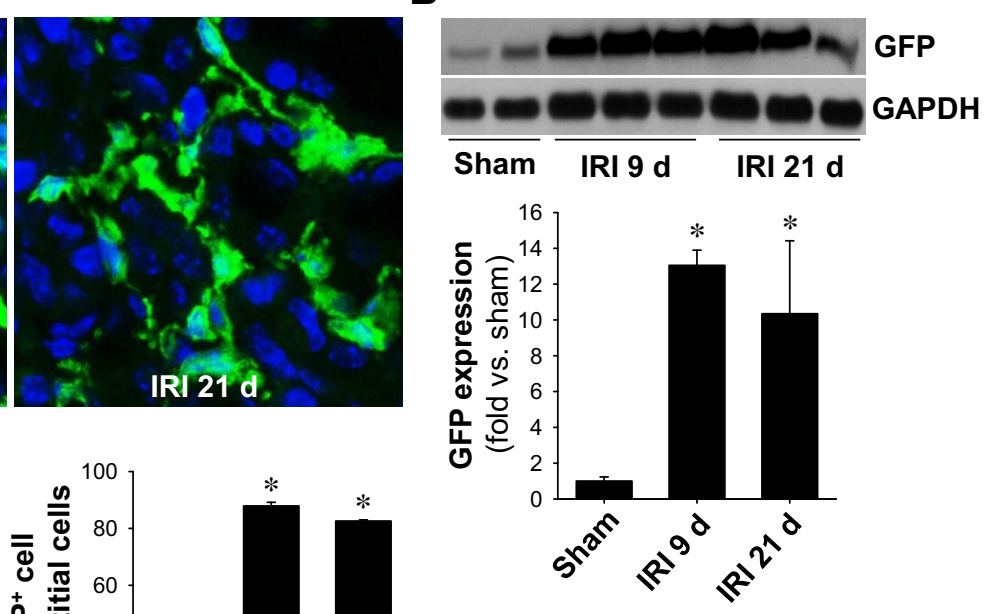

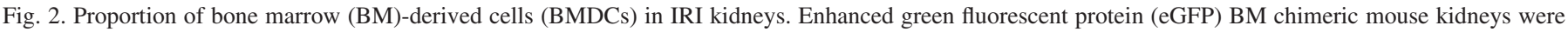

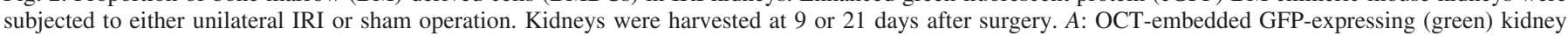

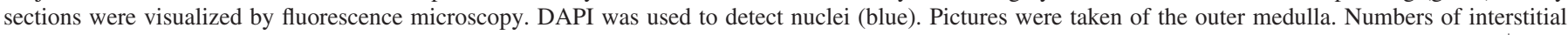

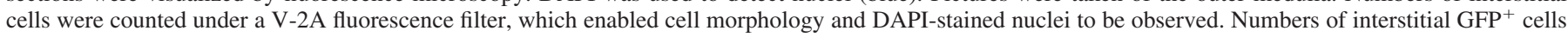

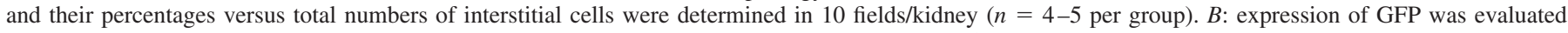

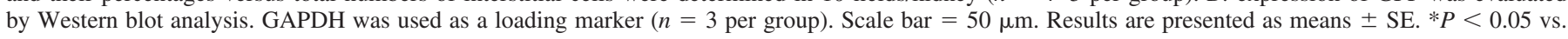
sham. 
of ECM proteins) by staining kidney sections with $\alpha$-SMA (a marker of myofibroblasts) antibody. The $\alpha$-SMA-positive area merged with GFP in the total $\alpha$-SMA-positive area was $16.6 \%$ and $14.5 \%$ at 9 and 21 days afte IRI, respectively (Fig. $3, A-C$ ). In serially sectioned tissue, triple-positive cells for GFP, $\alpha$-SMA, and collagen type III were observed (Fig. 3D), indicating that GFP-expressing cells play a role as functional fibroblasts. In support of this, expression levels of $\alpha$-SMA and collagen type III were elevated in IRI kidneys as evaluated by Western blot analysis (Fig. 3E). These results indicate that BMDCs play as major contributors in increased numbers of interstitial cells by moving to injured sites, differentiation into myofibroblasts, and production of ECM proteins, including collagen type III.

Recruitment and differentiation of BMDCs in IRI kidneys. Since ROS are associated with leukocyte infiltration into injured sites and their differentiation into other cells $(12,37,40)$, we examined whether apocynin (a NADPH oxidase inhibitor and antioxidant) influences the recruitment of BMDCs to IRI kidneys and their differentiation into fibroblasts. IRI increased the expression of Nox2 (a major source of ROS in phagocytic cells) in kidney tissues (Fig. 4A) $(6,33)$, and daily apocynin treatment significantly inhibited increases in interstitial cell numbers $(243.3 \pm 9.8$ with vehicle vs. $197.0 \pm 1.7$ with apocynin, $P<0.05$; Fig. 4, $B$ and $C$ ) and reduced GFP-positive cells $(222.1 \pm 9.7$ with vehicle vs. $176.8 \pm 0.8$ with apocynin, $P<0.05$; Fig. 4, $B$ and $D$ ). Although the expression of FSP-1 in several types of cells has recently been reported $(18,31)$, FSP-1 has been used as a marker protein of fibroblasts widely $(22,39)$. Daily apocynin treatment inhibited post-IRI increases in FSP-1-positive cells $(63.1 \pm 2.4$ with vehicle vs. $38.8 \pm 2.1$ with apocynin, $P<0.05$; Fig. $4 E$ ). Apocynin treatment also reduced the percentage of FSP-1-positive cells among total interstitial cells $(25.9 \pm 1.4$ with vehicle vs. $19.7 \pm 0.9$ with
A

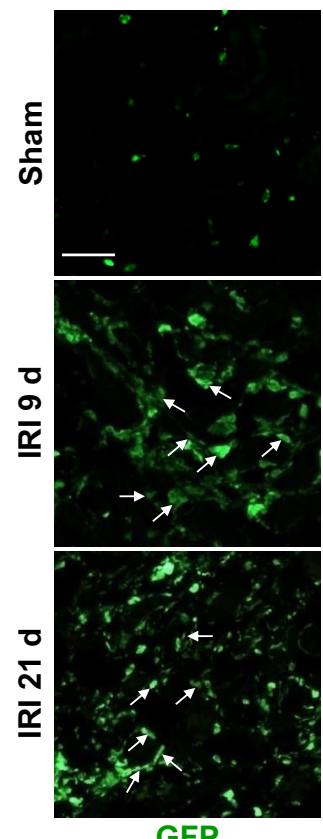

GFP

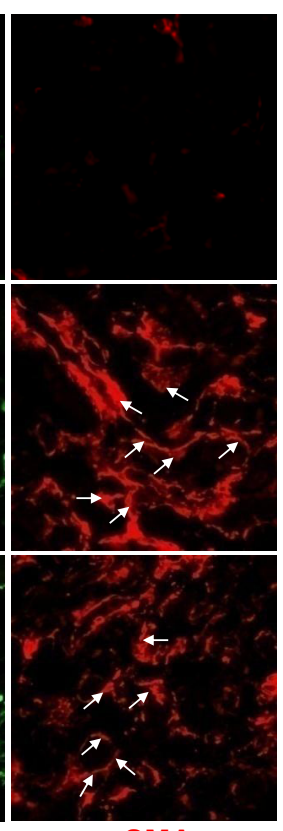

a-SMA

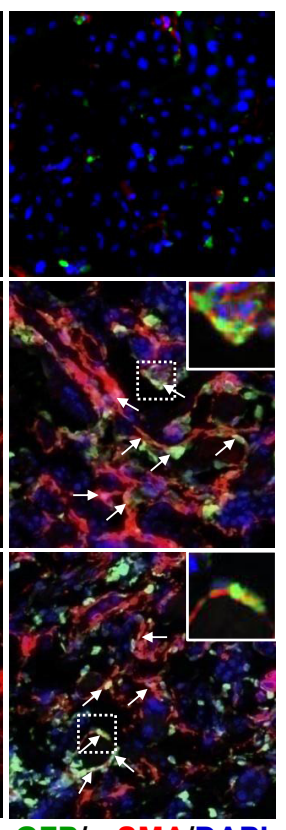

GFP/a-SMA/DAPI
B

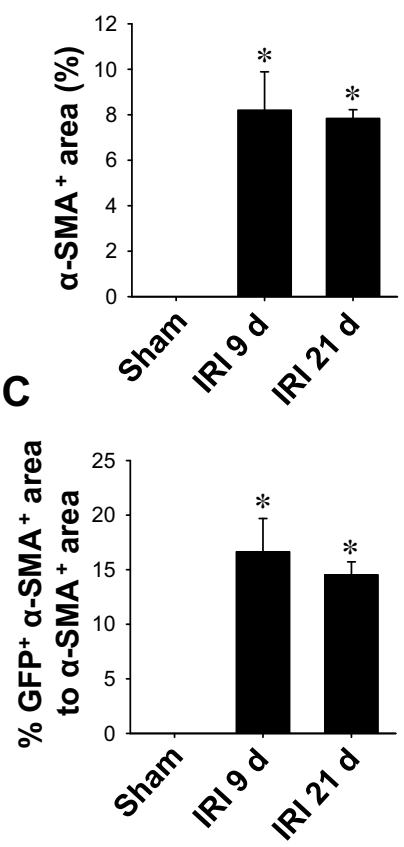

D

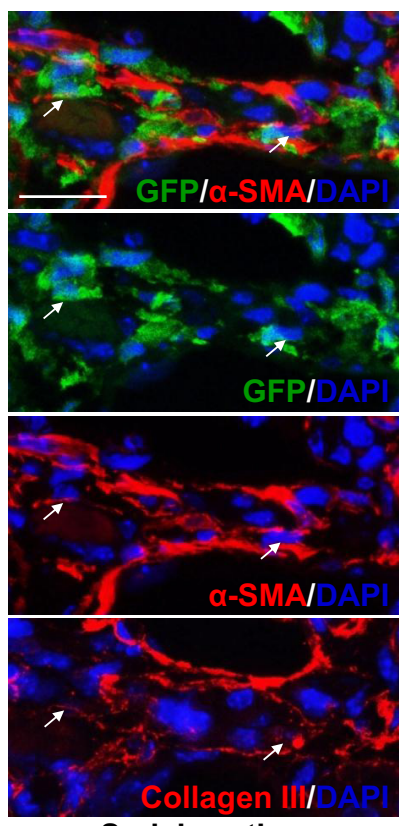

Serial section

$\mathbf{E}$
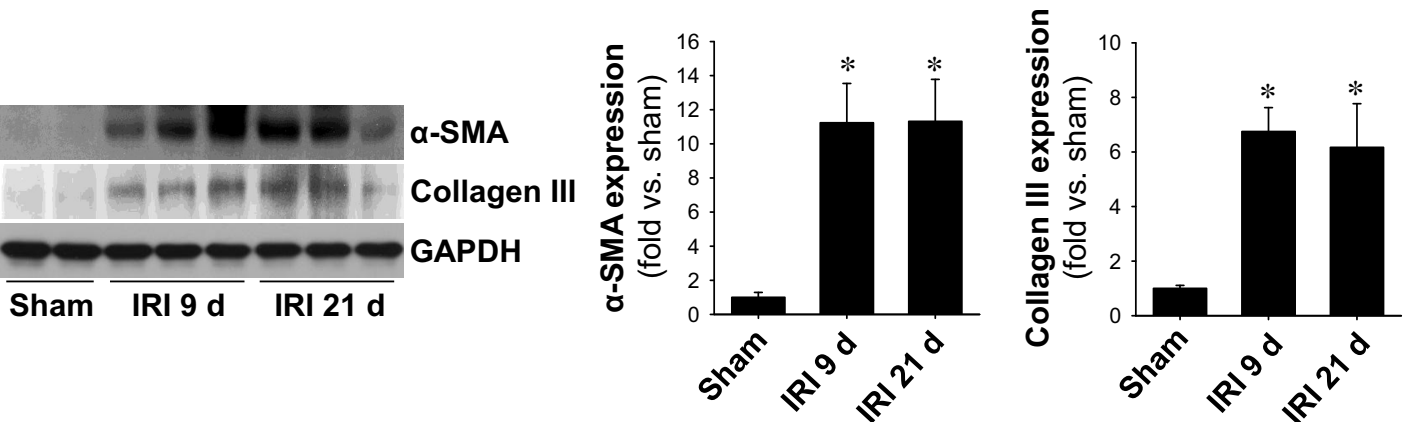

Fig. 3. Expression levels of fibrosis-related marker proteins in IRI kidneys. eGFP BM chimeric mouse kidneys were subjected to either unilateral IRI or sham operation. Kidneys were harvested at 9 or 21 days after surgery. A: OCT-embedded GFP-expressing (green) kidney sections were immunostained with anti- $\alpha$-smooth muscle actin ( $\alpha$-SMA; red) antibody. DAPI (blue) was used to detect nuclei. Pictures were taken of the outer medulla. Arrows indicate cells positive for GFP and $\alpha$-SMA. The insets are high-magnification images of the dotted rectangles. $B$ and $C$ : $\alpha$-SMA- and GFP-expressing $\alpha$-SMA-positive areas were calculated using i-solution software and determined in 10 fields/kidney $(n=4-5$ per group). $D$ : double-positive cell for $\alpha$-SMA and collagen type III (Col III) detected using immunofluorescent staining in a serially sectioned kidney. Arrows indicate cells with triple positivity for GFP, $\alpha$-SMA, and Col III. Scale bar $=50 \mu \mathrm{m}$. E: expression levels of $\alpha$-SMA and Col III were evaluated by Western blot analysis. GAPDH was used as a loading marker ( $n=3$ per group). Results are presented as means \pm SE. $* P<0.05$ vs. sham. 

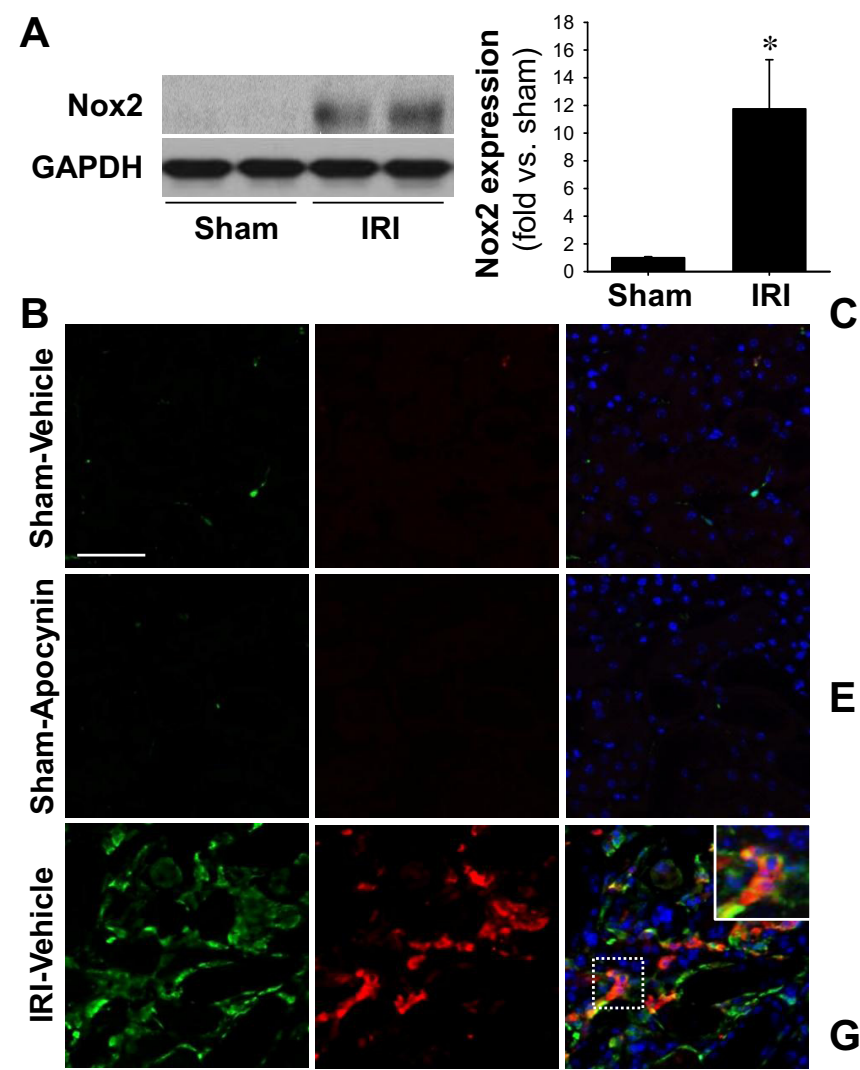

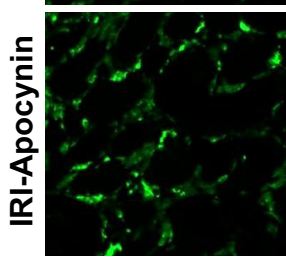

GFP
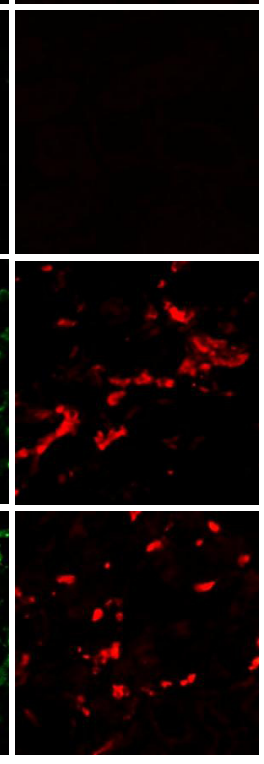

FSP-1

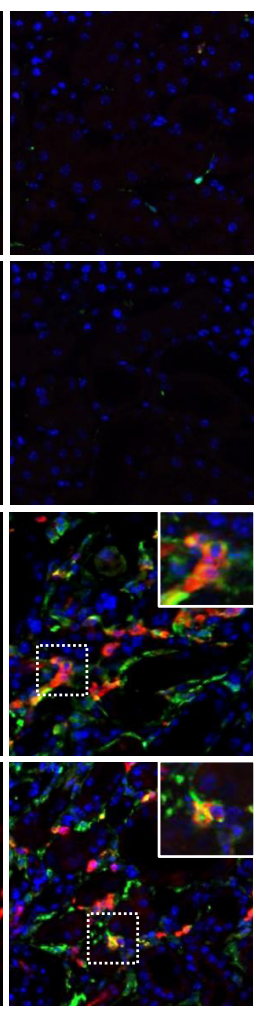

GFP/FSP-1/DAPI

\section{C}

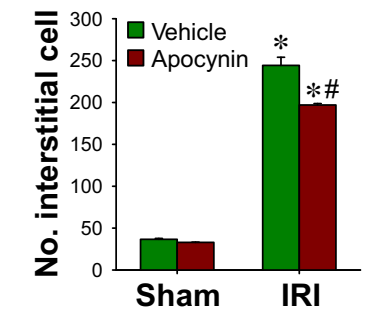

E

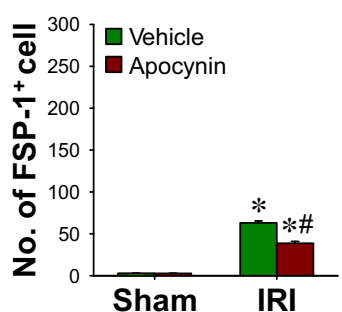

\section{G}

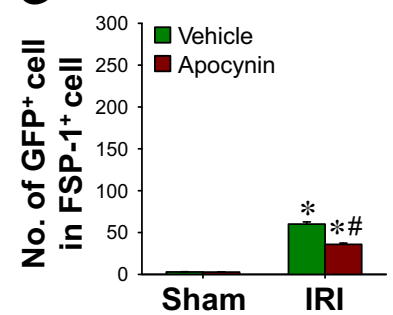

D
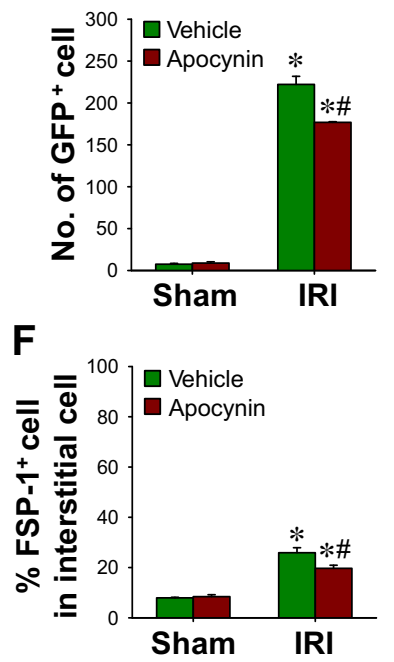

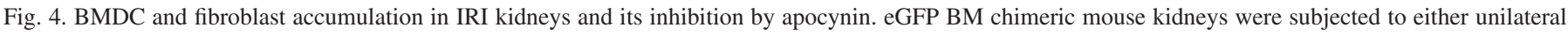

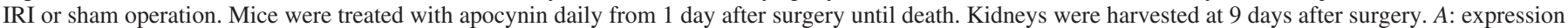

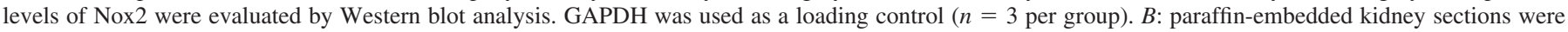

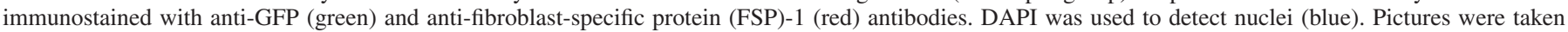

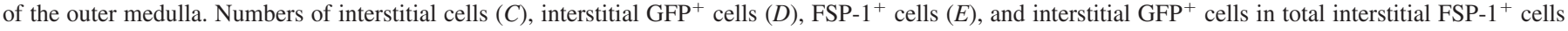

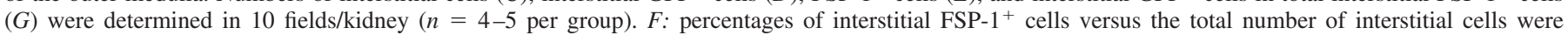

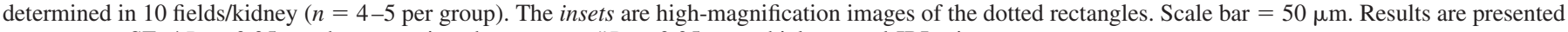
as means $\pm \mathrm{SE}$. $* P<0.05$ vs. the respective sham group; $\# P<0.05$ vs. vehicle-treated IRI mice.

apocynin, $P<0.05$; Fig. $4 F$ ). To further examine whether BMDCs exhibit fibroblastic features, we performed double staining using FSP-1 and GFP antibodies. About $95 \%$ of FSP-1-positive cells were found to be GFP positive, and doubly positive cell numbers were significantly reduced by apocynin treatment (Fig. $4 G$ ). These observations indicate that BMDCs are major sources of interstitial FSP-1-positive cells and that antioxidant treatment inhibits FSP-1-positive cell increases in the interstitium after IRI.

BMDCs proliferated in IRI kidneys. To determine whether increased interstitial cell levels in kidneys after IRI were due to the continuous recruitment of BMDCs or to the proliferation of BMDCs in sites of injury, we examined proliferation using BrdU incorporation, which is useful for identifying proliferating cells (22). BrdU-positive cells in the interstitium dramatically increased after IRI (Fig. 5, $A$ and $B$ ) and $>20 \%$ of interstitial cells were BrdU positive (Fig. 5A), showing that interstitial cells proliferated in fibrotic kidneys. Furthermore, increases in BrdU-positive cells were significantly reduced by daily apocynin treatment $(58.8 \pm 0.7$ with vehicle vs. $47.3 \pm$ 1.2 cell with apocynin, $P<0.05$; Fig. $5, A$ and $B$ ). Furthermore, $>80 \%$ of BrdU-positive cells were GFP positive (Fig. $5 C$ ), indicating that most proliferating interstitial cells originated from the BM. Apocynin reduced the number of doublepositive interstitial cells to GFP and BrdU in IRI kidneys (Fig. $5 C$ ). On the other hand, apocynin enhanced the number of tubular BrdU-positive cells in IRI kidneys $(39.6 \pm 2.5$ with vehicle vs. $51.1 \pm 0.2$ with apocynin, $P<0.05$; Fig. $5 D)$. Actually, total tubular cell numbers were significantly reduced by a half compared with those of normal kidneys after IRI $(202.6 \pm 9.9$ with vehicle vs. $116.1 \pm 0.8$ with apocynin, $P<$ $0.05)$, and this reduction was inhibited by apocynin in IRI 
A
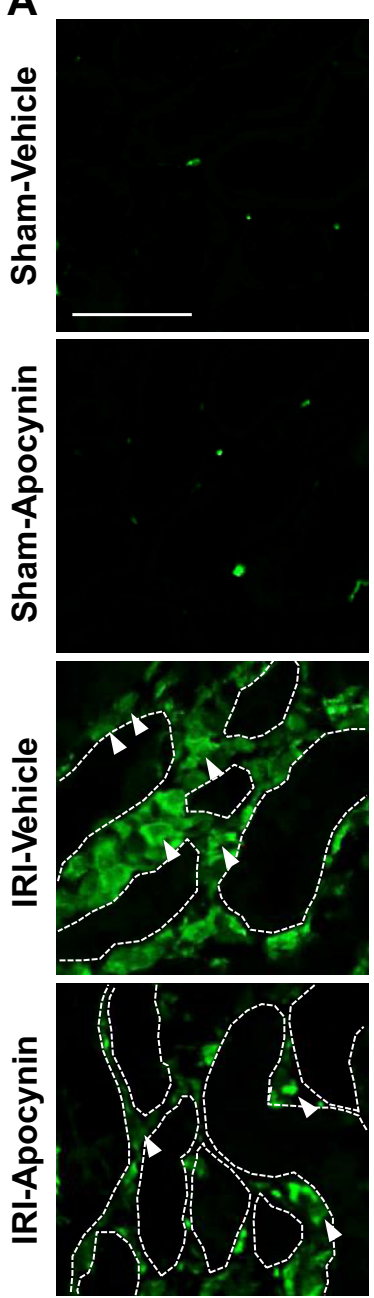

GFP
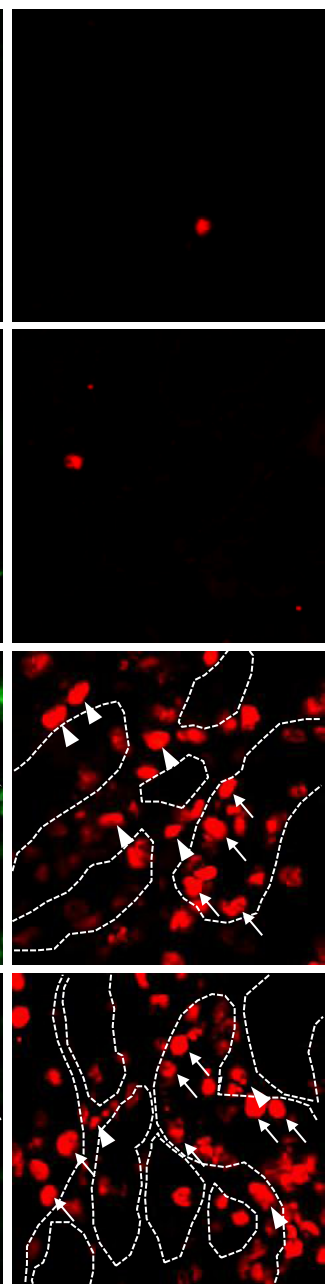

BrdU
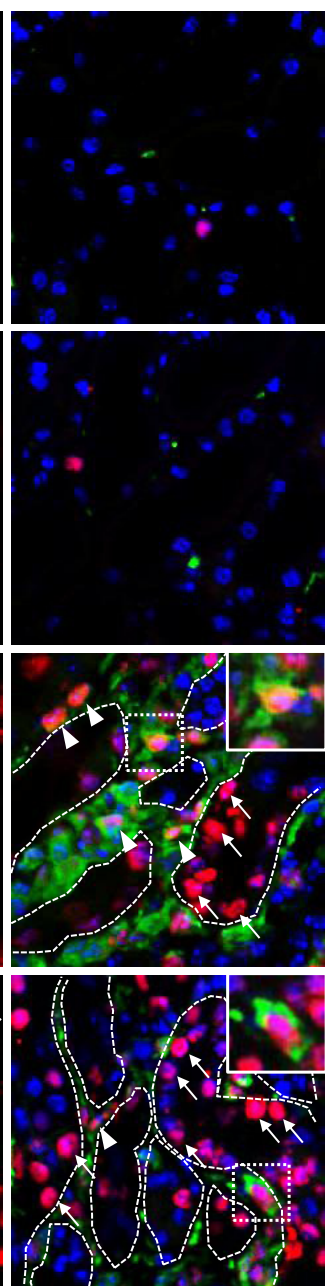

GFP/BrdU/DAPI
B
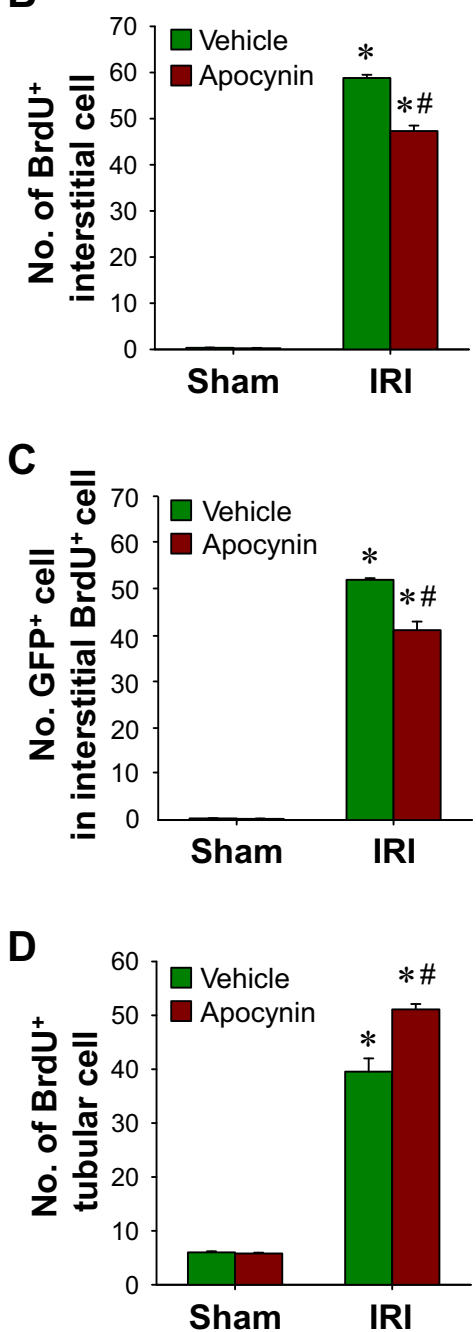

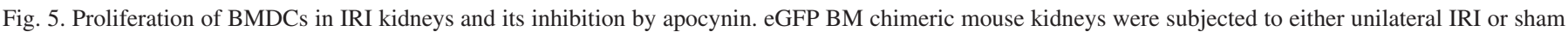

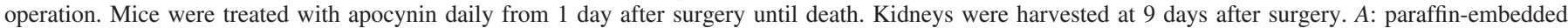

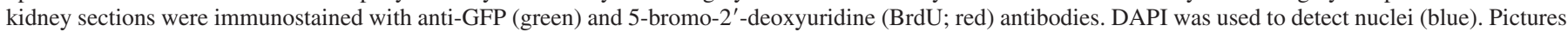

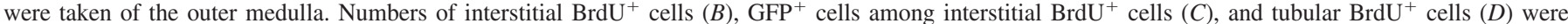

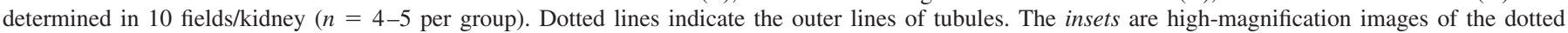

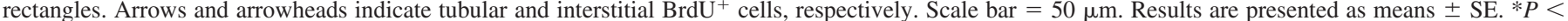
0.05 vs. the respective sham group; $\# P<0.05$ vs. vehicle-treated IRI mice.

kidneys compared with vehicle controls (116.1 \pm 0.8 with vehicle vs. $126.9 \pm 0.8$ with apocynin, $P<0.05)$. These results indicate that ROS play cell-specific roles, that is, ROS diminish tubule cell proliferation but increase interstitial cell proliferation.

Apocynin reduced the numbers of interstitial macrophages and collagen deposition in IRI kidneys. Because monocytes/ macrophages are major players in the process of fibrosis and they mainly originate from the $\operatorname{BM}(1,15,35,43)$, in the present study, we determined the numbers of macrophages in the interstitium using F4/80 antibody (a macrophage marker). As expected, F4/80-positive cell numbers were greatly increased in the kidney after IRI (Fig. 6, $A$ and $B$ ). Most of F4/80-positive macrophages were GFP positive (Fig. 6C), and F4/80-positive macrophages accounted for $\sim 35 \%$ of interstitial cells in kidneys 9 days are IRI (Fig. 6D). Apocynin significantly inhibited increases in F4/80-positive cells in IRI kidneys
(86.4 \pm 8.2 with vehicle vs. $54.7 \pm 8.0$ with apocynin, $P<$ 0.05 ; Fig. $6 B$ ). These results indicate that most macrophages in the interstitium originate from the $\mathrm{BM}$ and that ROS/oxidative stress are associated with the recruitment of macrophages. As observed for F4/80, numbers of Nox2-positive cells were much increased in IRI kidneys (Fig. 7, $A$ and $B$ ) and accounted for $34.3 \%$ of total interstitial cells (Fig. $7 A$ ). It is known that Nox2 is predominantly expressed in phagocytic cells, although it has also been shown to be expressed in fibroblasts, endothelial cells, and kidney cells (6). Apocynin significantly inhibited the postischemic increase of Nox2-positive cells in the kidney $(83.9 \pm 5.6$ with vehicle vs. $59.1 \pm 4.4$ with apocynin, $P<$ 0.05; Fig. 7B). Furthermore, most Nox2-positive cells coexpressed GFP (Fig. 7C). These findings show that the infiltration of BM-originated phagocytic cells plays an important role in the progression of fibrosis and that ROS regulate the recruitment of phagocytic cells into IRI kidneys. 
A
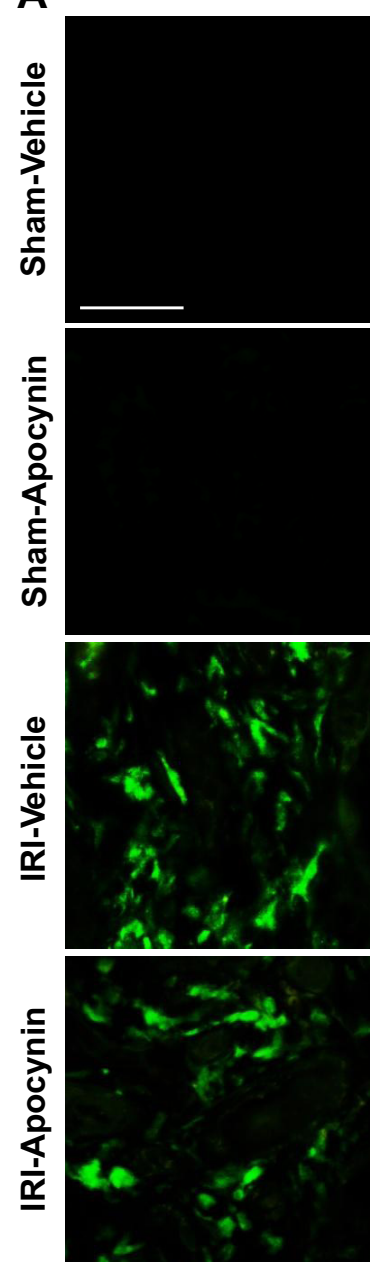

GFP
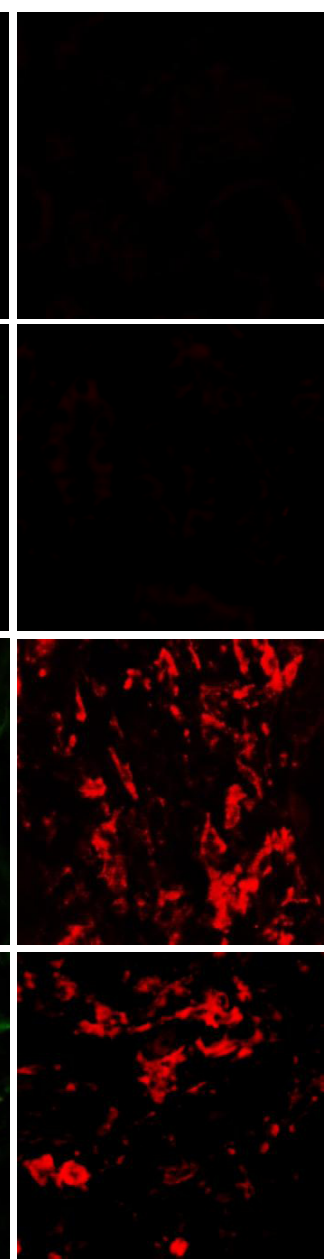

$\mathrm{F} 4 / 80$
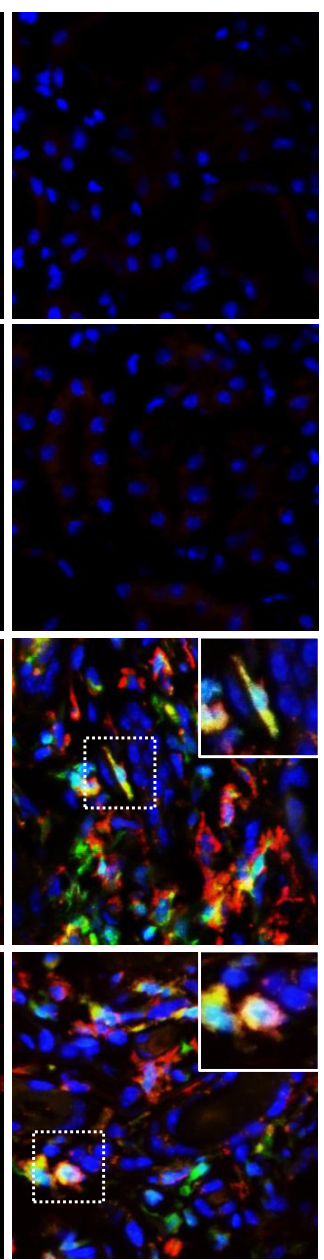

GFP/F4/80/DAPI
B
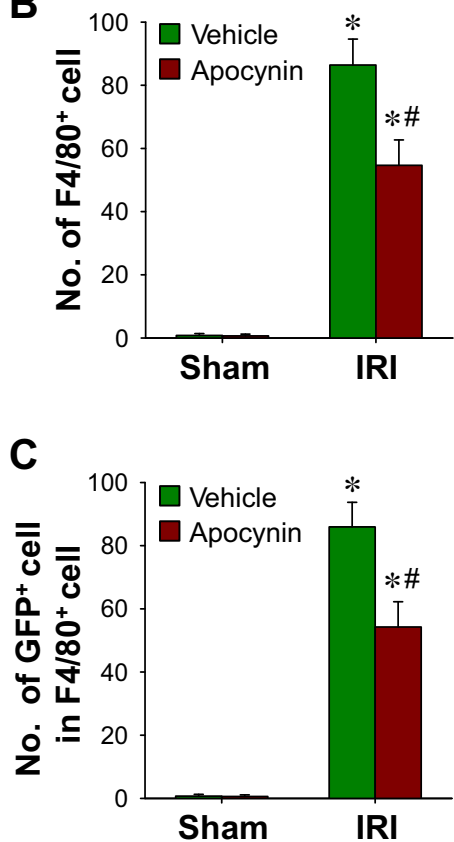

D

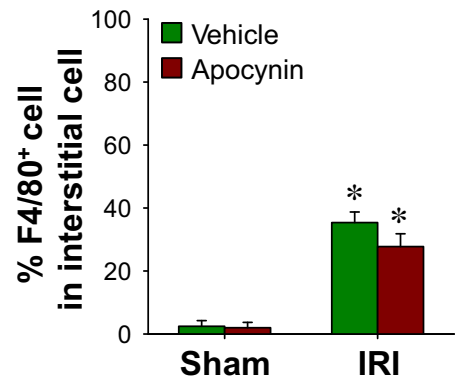

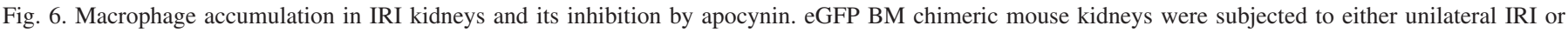

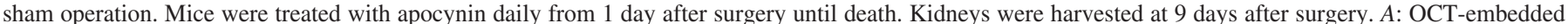

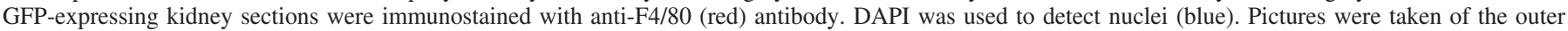

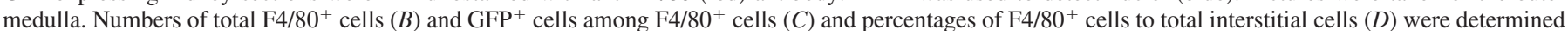

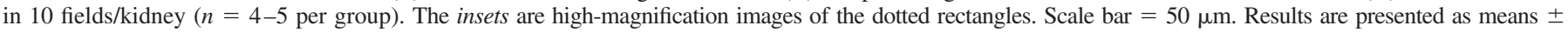
SE. $* P<0.05$ vs. sham; $\# P<0.05$ vs. vehicle-treated IRI mice.

Finally, to determine whether BMDC numbers in the interstitium are related to kidney fibrosis after IRI, we investigated collagen type III deposition. After IRI, both GFP- and collagen type III-positive areas dramatically increased in the interstitium of IRI kidneys (Fig. 8). Apocynin significantly inhibited these post-IRI increases in GFP-positive areas $(25.9 \pm 0.2$ with vehicle vs. $20.7 \pm 0.7$ with apocynin, $P<0.05$; Fig. $8 B$ ) and in collagen type III-positive areas (12.11 \pm 0.02 with vehicle vs. $9.38 \pm 0.24$ with apocynin, $P<0.05$; Fig. $8 C$ ), indicating the existence of a positive relation between BMDC levels and kidney fibrosis.

\section{DISCUSSION}

Our results suggest that inhibition of BMDC recruitment to sites of injury and their subsequent proliferation and differentiation offers a potential means to prevent IRI-induced kidney fibrosis. Furthermore, our findings indicate that the elucidation of the underlying mechanisms of cell-specific responses to antioxidants might aid the future development of therapeutics for kidney fibrosis. This view is supported by the following: 1) GFP-positive BMDCs infiltrated the interstitium of IRI kidneys and comprised a major portion of the interstitial cell population; 2) GFP-positive cells expressed $\alpha$-SMA, FSP-1, and collagen type III, indicating that BMDCs differentiated into fibrosis-inducing cells; 3) GFP-positive cells proliferated in sites of injury; and 4) the above changes were inhibited by daily apocynin treatment, which mitigated kidney fibrosis.

Basile et al. (4) reported FSP-1 in the expanded interstitium of IRI kidneys that achieved functional recovery. We also observed that FSP-1-positive cells were predominately localized among interstitial cells around injured tubules and that tubular epithelial cells were rarely FSP-1 positive $(22,24,26)$. In addition, BM-derived $\alpha$-SMA-positive cells expressed collagen type III, suggesting that BMDCs differentiate to functional fibroblasts. In this study, BMDCs accounted for $>80 \%$ of interstitial cells in IRI-induced fibrotic kidneys, and BMDCs 
A
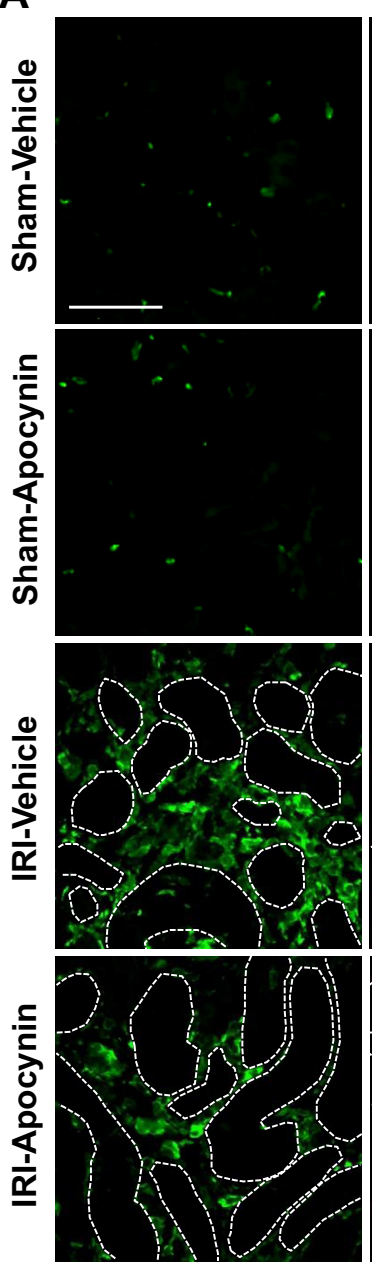

GFP
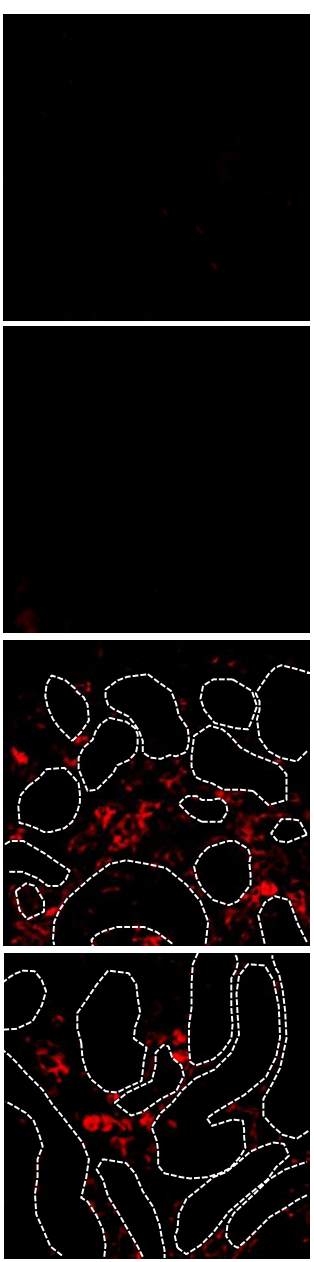

Nox2
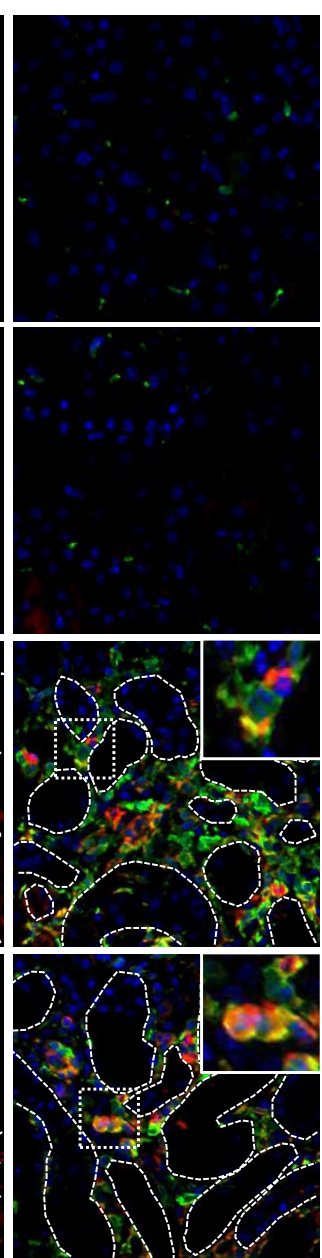

GFP/Nox2/DAPI
B

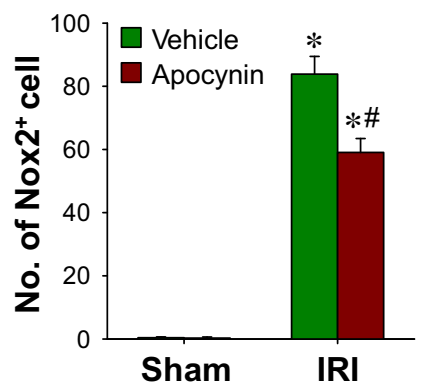

C

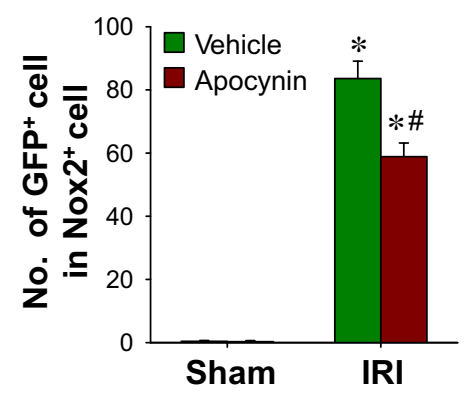

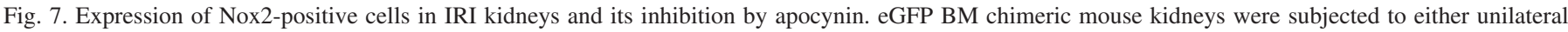

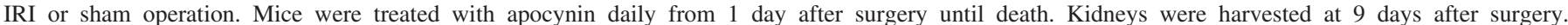

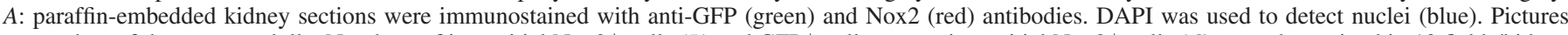

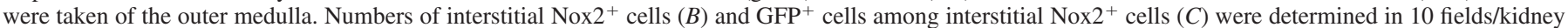

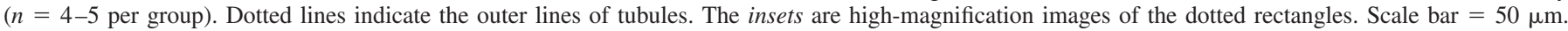
Results are presented as means \pm SE. $* P<0.05$ vs. sham; $\# P<0.05$ vs. vehicle-treated IRI mice.

expressed FSP-1 ( 24.6\% on total BMDCs $)$ and $\alpha$-SMA ( $\sim 16.6 \%$ of the total $\alpha$-SMA-positive area). The percentages of GFP-expressing FSP-1-positive cells and $\alpha$-SMA were relatively less in total GFP-positive cells, perhaps due to the proliferation of GFP-positive cells. These observations indicate that BMDCs are major contributors to the IRI-induced expansion of the interstitium and that they differentiate to fibroblasts and myofibroblasts. Broekema et al. (8) reported that approximately one-third of myofibroblasts found in IRI kidneys originated from the BM, and, in another study (29), >30\% of myofibroblasts in adriamycin-induced fibrotic kidneys were found to be derived from the BM. Recently, we (22) reported that $55.8 \%$ of FSP-1-positive fibroblasts in UUO-induced fibrotic kidneys were of BM origin. Furthermore, the findings of the present study suggest that BMDCs are important sources of fibroblasts during kidney fibrosis.

Interstitial cell proliferation is as important as the differentiation of recruited and kidney-resided cells in the context of kidney fibrosis (7). In the present study, BrdU-positive cells constituted $>20 \%$ of all interstitial cells and, among them, $>88 \%$ were GFP positive, indicating that $12 \%$ of proliferating cells were of non-BM origin and that kidney resident cellderived and resident fibroblasts had a minor effect on IRIinduced fibrosis progression. This finding suggests that BMDCs possessed great proliferative competence in sites of injury and played a critical role in increasing interstitial cell numbers through differentiation and proliferation, although it should be added that it is possible that circulating BrdU-labeled BMDCs could have been recruited into kidney interstitium. These results concur with those of our previous study (22), in which $\sim 90 \%$ of BrdU-positive cells in the kidney interstitium were found to originate from the BM in UUO-induced kidney fibrosis.

Oxidative stress is deeply associated with the initiation and progression of kidney fibrosis $(10,23,26,36)$, and a number of studies have described the pathological consequences of kidney IRI-induced ROS $(36,37)$. Several studies $(10,24,26,32)$ have demonstrated that inhibition of ROS production and 
A
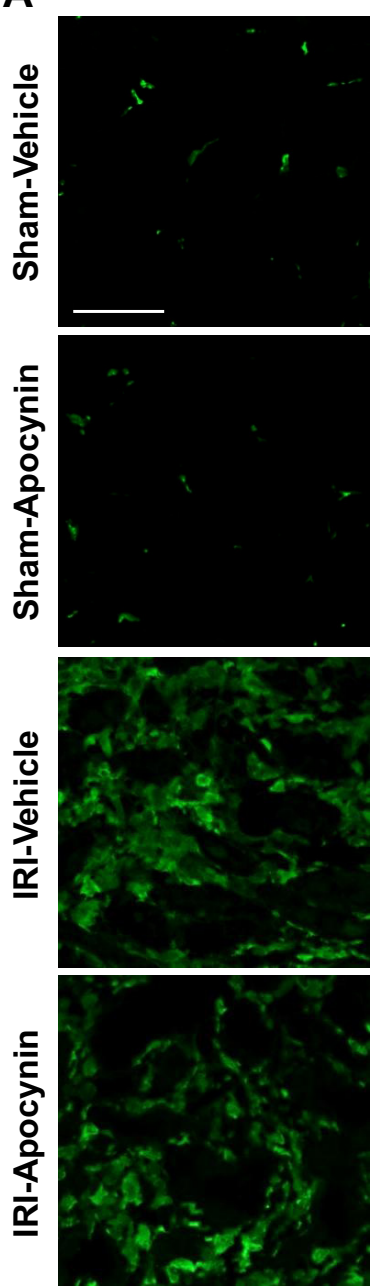

GFP
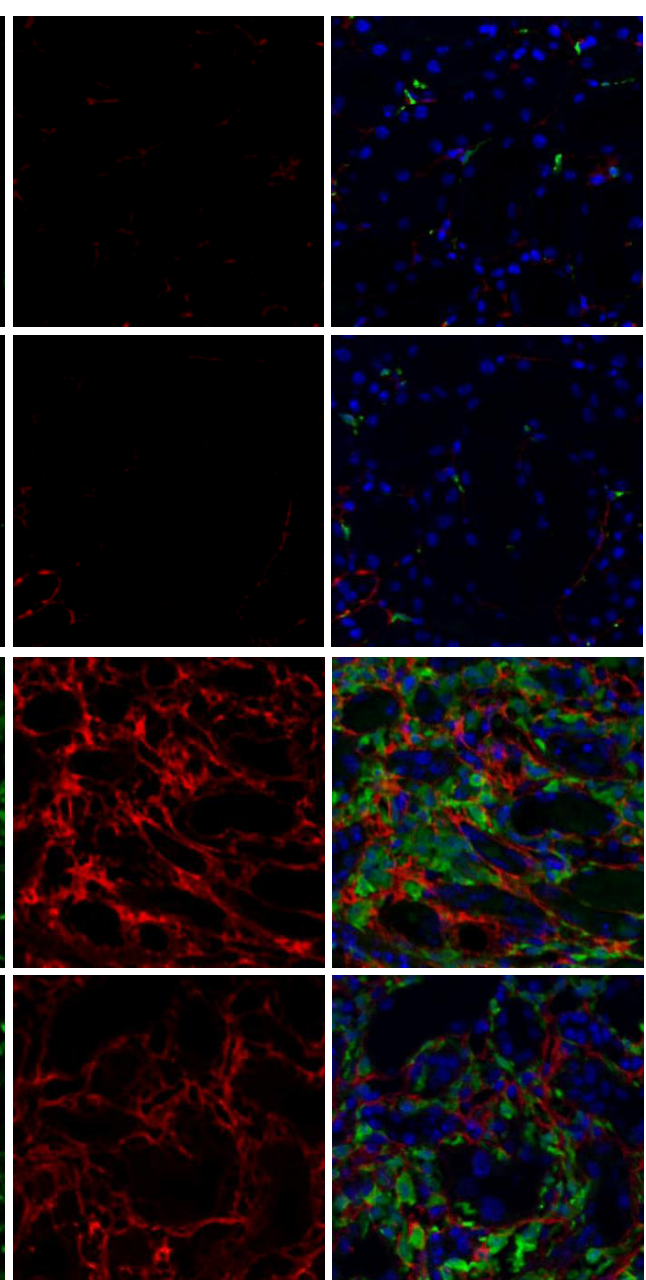

Col III
B

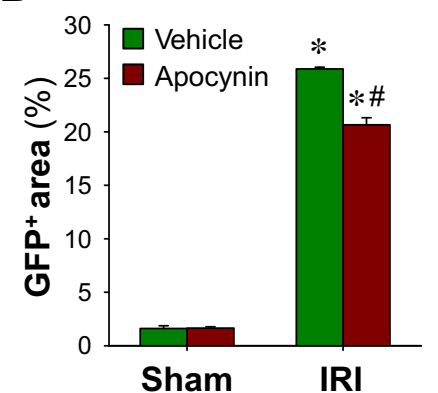

C

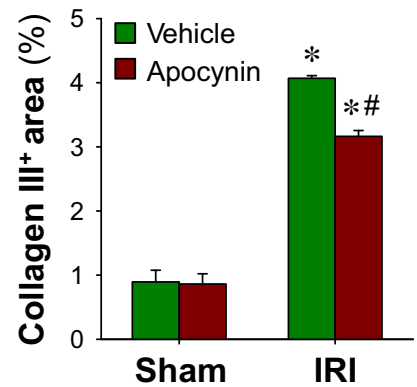

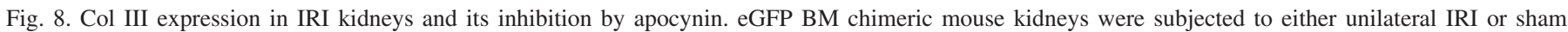

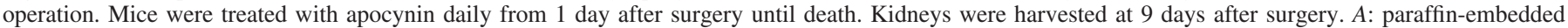

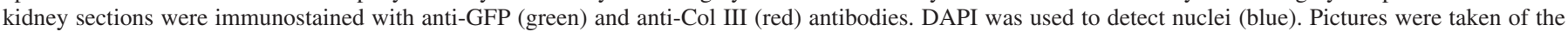

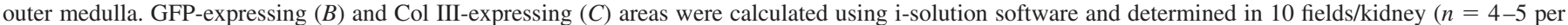
group). Scale bar $=50 \mu \mathrm{m}$. Results are presented as means \pm SE. ${ }^{*} P<0.05$ vs. the respective sham group; \#P<0.05 vs. vehicle-treated IRI mice.

enhancement of ROS scavenging ameliorates kidney fibrosis by suppressing inflammation and oxidative stress. Recently, we (26) found intrarenal ROS elevation after IRI was sustained for $>2 \mathrm{wk}$ and that antioxidant treatment reduced kidney fibrosis after IRI. In the present study, we found that apocynin effectively inhibited post-IRI increases in interstitial cells, that is, of GFP-, FSP-1-, $\alpha$-SMA-, F4/80-, and Nox2-positive cells. In addition, apocynin reduced the proliferation of interstitial cells. These findings show that ROS/oxidative stress regulate the recruitment of BMDCs into injured kidneys and the proliferation and differentiation of BMDCs in the infiltrated site. In the UUO model, we (22) previously found that apocynin attenuated kidney fibrosis by inhibiting the recruitment of BMDCs into injured kidneys and their subsequent proliferation and differentiation. More recently, we and others $(24,26,32,38)$ reported that antioxidant administration suppresses kidney fibrosis by reducing interstitial Nox2 expression, oxidative stress, and macrophage recruitment into the interstitium. Nox2 is expressed primarily in BMDCs (6) and regulates the recruit- ment of BMDCs by damaged tissues (41). Djamali et al. (14) reported that Nox 2 is expressed by macrophages in interstitial cells and that it plays a critical role to the progression of chronic allograft nephropathy-related kidney fibrosis. In the present study, IRI triggered increases in Nox 2 expression by $>30 \%$ of kidney interstitial cells at 9 days after IRI, and this was suppressed by apocynin, which suggests the recruitment of Nox2-positive cells into IRI kidneys contributes to IRI-induced kidney fibrosis.

Monocytes/macrophages have been regarded to be the main contributors to kidney fibrosis by directly the induction of kidney fibrosis and by supporting fibrotic progression via the inflammatory response and secretions of profibrotic cytokines $(7,22,27,30)$. In the present study, F4/80-positive macrophages were much increased and accounted for $35 \%$ of total interstitial cells at 9 days after IRI. Furthermore, the population of macrophages recruited by IRI kidneys was significantly reduced by apocynin. These observations suggest that understanding of the regulatory roles played by BM-derived mono- 
cytes/macrophages in kidney fibrosis would facilitate the development of therapeutics. In a previous study (22), we also found the removal of macrophages by irradiation attenuated kidney fibrosis, whereas the reconstitution of macrophage numbers using RAW 264.7 cells in irradiated mice reversed the antifibrotic effect of irradiation.

Recently, we (24) reported that $\mathrm{Mn}$ (III) tetrakis(1-methyl-4pyridyl)porphyrin (an antioxidant and mimetic of superoxide dismutase) supplementation enhances IRI-induced tubule proliferation but inhibits interstitial proliferation. Similarly, in the present study, we found that apocynin inhibited interstitial cell proliferation but enhanced tubular cell proliferation. Anikumar et al. (2) reported that Nox2 levels are cell specific and that this results in different levels of intracellular ROS and different cell responses. Several other authors $(2,9,13)$ have concluded that the effects of ROS on cell proliferation are cell type specific, even in the same tissues. Furthermore, in a previous study (19), we found that inhibition of ERK activation during the recovery phase after IRI accelerated tubular cell proliferation but prevented interstitial cell proliferation. These findings suggest that the definition of cell-specific roles is required for the development of therapeutics in specific diseases.

\section{GRANTS}

This work was supported by the Basic Science Research program through the National Research Foundation of Korea funded by Ministry of Education, Science and Technology Grant 2012002592 (to K. M. Park).

\section{DISCLOSURES}

No conflicts of interest, financial or otherwise, are declared by the author(s).

\section{AUTHOR CONTRIBUTIONS}

Author contributions: H.-S.J. and K.M.P. conception and design of research; H.-S.J. and S.J.H. performed experiments; H.-S.J. and S.J.H. analyzed data; H.-S.J., J.I.K., and K.M.P. interpreted results of experiments; H.-S.J. prepared figures; H.-S.J. drafted manuscript; H.-S.J., J.I.K., and K.M.P. edited and revised manuscript; H.-S.J., J.I.K., S.J.H., and K.M.P. approved final version of manuscript.

\section{REFERENCES}

1. Anders HJ, Ryu M. Renal microenvironments and macrophage phenotypes determine progression or resolution of renal inflammation and fibrosis. Kidney Int 80: 915-925, 2011.

2. Anilkumar N, Weber R, Zhang M, Brewer A, Shah AM. Nox4 and nox2 NADPH oxidases mediate distinct cellular redox signaling responses to agonist stimulation. Arterioscler Thromb Vasc Biol 28: 1347-1354, 2008.

3. Asaba K, Tojo A, Onozato ML, Goto A, Quinn MT, Fujita T, Wilcox CS. Effects of NADPH oxidase inhibitor in diabetic nephropathy. Kidney Int 67: 1890-1898, 2005.

4. Basile DP, Fredrich K, Alausa M, Vio CP, Liang M, Rieder MR, Greene AS, Cowley AW Jr. Identification of persistently altered gene expression in the kidney after functional recovery from ischemic acute renal failure. Am J Physiol Renal Physiol 288: F953-F963, 2005.

5. Basile DP, Leonard EC, Beal AG, Schleuter D, Friedrich J. Persistent oxidative stress following renal ischemia-reperfusion injury increases ANG II hemodynamic and fibrotic activity. Am J Physiol Renal Physiol 302: F1494-F1502, 2012.

6. Bedard K, Krause KH. The NOX family of ROS-generating NADPH oxidases: physiology and pathophysiology. Physiol Rev 87: 245-313, 2007.

7. Bonventre JV, Yang L. Cellular pathophysiology of ischemic acute kidney injury. J Clin Invest 121: 4210-4221, 2011.

8. Broekema M, Harmsen MC, van Luyn MJ, Koerts JA, Petersen AH, van Kooten TG, van Goor H, Navis G, Popa ER. Bone marrow-derived myofibroblasts contribute to the renal interstitial myofibroblast population and produce procollagen I after ischemia/reperfusion in rats. $J$ Am Soc Nephrol 18: 165-175, 2007.

9. Campisi J. Senescent cells, tumor suppression, and organismal aging: good citizens, bad neighbors. Cell 120: 513-522, 2005.

10. Chade AR, Rodriguez-Porcel M, Herrmann J, Zhu X, Grande JP, Napoli C, Lerman A, Lerman LO. Antioxidant intervention blunts renal injury in experimental renovascular disease. J Am Soc Nephrol 15: 958-966, 2004.

11. Chevalier RL, Thornhill BA, Forbes MS, Kiley SC. Mechanisms of renal injury and progression of renal disease in congenital obstructive nephropathy. Pediatr Nephrol 25: 687-697, 2010.

12. D'Autreaux B, Toledano MB. ROS as signalling molecules: mechanisms that generate specificity in ROS homeostasis. Nat Rev Mol Cell Biol 8: 813-824, 2007.

13. De Minicis S, Bataller R, Brenner DA. NADPH oxidase in the liver: defensive, offensive, or fibrogenic? Gastroenterology 131: 272-275, 2006.

14. Djamali A, Vidyasagar A, Adulla M, Hullett D, Reese S. Nox-2 is a modulator of fibrogenesis in kidney allografts. Am J Transplant 9: 74-82, 2009.

15. Duffield JS. Macrophages and immunologic inflammation of the kidney. Semin Nephrol 30: 234-254, 2010.

16. Duffield JS, Park KM, Hsiao LL, Kelley VR, Scadden DT, Ichimura T, Bonventre JV. Restoration of tubular epithelial cells during repair of the postischemic kidney occurs independently of bone marrow-derived stem cells. $J$ Clin Invest 115: 1743-1755, 2005.

17. Humphreys BD, Lin SL, Kobayashi A, Hudson TE, Nowlin BT, Bonventre JV, Valerius MT, McMahon AP, Duffield JS. Fate tracing reveals the pericyte and not epithelial origin of myofibroblasts in kidney fibrosis. Am J Pathol 176: 85-97, 2010.

18. Inoue T, Plieth D, Venkov CD, Xu C, Neilson EG. Antibodies against macrophages that overlap in specificity with fibroblasts. Kidney Int 67: 2488-2493, 2005

19. Jang HS, Han SJ, Kim JI, Lee S, Lipschutz JH, Park KM. Activation of ERK accelerates repair of renal tubular epithelial cells, whereas it inhibits progression of fibrosis following ischemia/reperfusion injury. Biochim Biophys Acta 1832: 1998-2008, 2013.

20. Jang HS, Kim J, Kim KY, Kim JI, Cho MH, Park KM. Previous ischemia and reperfusion injury results in resistance of the kidney against subsequent ischemia and reperfusion insult in mice; a role for the Akt signal pathway. Nephrol Dial Transplant 27: 3762-3770, 2012.

21. Jang HS, Kim J, Park YK, Park KM. Infiltrated macrophages contribute to recovery after ischemic injury but not to ischemic preconditioning in kidneys. Transplantation 85: 447-455, 2008.

22. Jang HS, Kim JI, Jung KJ, Kim J, Han KH, Park KM. Bone marrow-derived cells play a major role in kidney fibrosis via proliferation and differentiation in the infiltrated site. Biochim Biophys Acta 1832: 817-825, 2013.

23. Jung KJ, Jang HS, Kim JI, Han SJ, Park JW, Park KM. Involvement of hydrogen sulfide and homocysteine transsulfuration pathway in the progression of kidney fibrosis after ureteral obstruction. Biochim Biophys Acta 1832: 1989-1997, 2013.

24. Kim J, Jung KJ, Park KM. Reactive oxygen species differently regulate renal tubular epithelial and interstitial cell proliferation after ischemia and reperfusion injury. Am J Physiol Renal Physiol 298: F1118-F1129, 2010.

25. Kim J, Kim JI, Na YK, Park KM. Intra-renal slow cell-cycle cells contribute to the restoration of kidney tubules injured by ischemia/ reperfusion. Anat Cell Biol 44: 186-193, 2011.

26. Kim J, Seok YM, Jung KJ, Park KM. Reactive oxygen species/ oxidative stress contributes to progression of kidney fibrosis following transient ischemic injury in mice. Am J Physiol Renal Physiol 297: F461-F470, 2009.

27. Ko GJ, Boo CS, Jo SK, Cho WY, Kim HK. Macrophages contribute to the development of renal fibrosis following ischaemia/reperfusion-induced acute kidney injury. Nephrol Dial Transplant 23: 842-852, 2008.

28. LeBleu VS, Taduri G, O'Connell J, Teng Y, Cooke VG, Woda C, Sugimoto H, Kalluri R. Origin and function of myofibroblasts in kidney fibrosis. Nat Med 19: 1047-1053, 2013.

29. Li J, Deane JA, Campanale NV, Bertram JF, Ricardo SD. The contribution of bone marrow-derived cells to the development of renal interstitial fibrosis. Stem Cells 25: 697-706, 2007.

30. Lin SL, Castano AP, Nowlin BT, Lupher ML Jr, Duffield JS. Bone marrow Ly6Chigh monocytes are selectively recruited to injured kidney 
and differentiate into functionally distinct populations. J Immunol 183: 6733-6743, 2009.

31. Lin SL, Kisseleva T, Brenner DA, Duffield JS. Pericytes and perivascular fibroblasts are the primary source of collagen-producing cells in obstructive fibrosis of the kidney. Am J Pathol 173: 1617-1627, 2008.

32. Liu F, Wei CC, Wu SJ, Chenier I, Zhang SL, Filep JG, Ingelfinger JR, Chan JS. Apocynin attenuates tubular apoptosis and tubulointerstitial fibrosis in transgenic mice independent of hypertension. Kidney Int 75: 156-166, 2009.

33. Nauseef WM. Biological roles for the NOX family NADPH oxidases. $J$ Biol Chem 283: 16961-16965, 2008.

34. Park KM, Chen A, Bonventre JV. Prevention of kidney ischemia/ reperfusion-induced functional injury and JNK, p38, and MAPK kinase activation by remote ischemic pretreatment. J Biol Chem 276: 1187011876, 2001

35. Ricardo SD, van Goor H, Eddy AA. Macrophage diversity in renal injury and repair. J Clin Invest 118: 3522-3530, 2008.

36. Rodriguez-Iturbe B, Vaziri ND, Herrera-Acosta J, Johnson RJ. Oxidative stress, renal infiltration of immune cells, and salt-sensitive hypertension: all for one and one for all. Am J Physiol Renal Physiol 286: F606-F616, 2004
37. Sedeek M, Nasrallah R, Touyz RM, Hebert RL. NADPH oxidases, reactive oxygen species, and the kidney: friend and foe. J Am Soc Nephrol 24: 1512-1518, 2013.

38. Shi XY, Hou FF, Niu HX, Wang GB, Xie D, Guo ZJ, Zhou ZM, Yang F, Tian JW, Zhang X. Advanced oxidation protein products promote inflammation in diabetic kidney through activation of renal nicotinamide adenine dinucleotide phosphate oxidase. Endocrinology 149: 1829-1839, 2008.

39. Sugimoto H, Mundel TM, Kieran MW, Kalluri R. Identification of fibroblast heterogeneity in the tumor microenvironment. Cancer Biol Ther 5: 1640-1646, 2006.

40. Thannickal VJ, Fanburg BL. Reactive oxygen species in cell signaling. Am J Physiol Lung Cell Mol Physiol 279: L1005-L1028, 2000.

41. Urao N, McKinney RD, Fukai T, Ushio-Fukai M. NADPH oxidase 2 regulates bone marrow microenvironment following hindlimb ischemia: role in reparative mobilization of progenitor cells. Stem Cells 30: 923-934, 2012.

42. Wynn TA. Cellular and molecular mechanisms of fibrosis. J Pathol 214: 199-210, 2008.

43. Wynn TA, Barron L. Macrophages: master regulators of inflammation and fibrosis. Semin Liver Dis 30: 245-257, 2010.

44. Zeisberg M, Duffield JS. Resolved: EMT produces fibroblasts in the kidney. J Am Soc Nephrol 21: 1247-1253, 2010

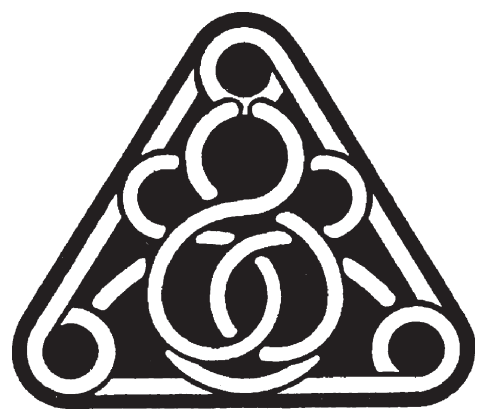

